\title{
Comparison of Apically Extruded Debris during Retreatment Procedure by Two Types of Endodontic Instruments
}

\author{
Mannu Vikram
}

\begin{abstract}
Introduction: During root canal treatment, canal debris is inadvertently extruded through the apex during shaping and cleaning. This happens not only during the routine endodontic cases, but also during the retreatment cases.
\end{abstract}

Objective: This study analyzed in vitro the amount of debris extruded through the foramen using two instrumentation techniques during endodontic retreatment.

Materials and methods: Sixty roots of mandibular first premolars were selected, instrumented with anatomical diameter up to size number 40 International Organization for Standardization (ISO) file, and then obturated with gutta-percha and zinc-oxide eugenol sealer by lateral condensation. They were then divided into two groups of 30 each. The first group was instrumented with ISO K-files for gutta-percha removal and the second group was instrumented with Protaper retreatment files and guttapercha was removed. All teeth were irrigated with distilled water. The debris extruded through the foramen were collected and weighed by an analytical balance.

Results: Group II had the lowest average for material extrusion through the foramen followed by group I. When Tukey test for statistical analysis was applied, significant differences among groups were found $(p=0.02)$.

Conclusion: It can be concluded that Protaper retreatment files produce significantly less debris as compared with K-files.

Keywords: Apical extrusion, Protaper, Retreatment.

How to cite this article: Vikram M. Comparison of Apically Extruded Debris during Retreatment Procedure by Two Types of Endodontic Instruments. Int J Recent Surg Med Sci 2017;3(1):7-9.

\section{Source of support: Nil}

Conflict of interest: None

\section{INTRODUCTION}

Endodontic therapy depends upon several parameters, which includes proper cleaning and shaping of the root canal system. During root canal instrumentation, root canal debris may be pushed inadvertently beyond the

\section{Associate Professor}

Department of Conservative Dentistry and Endodontics B.P. Koirala Institute of Health Sciences, Dharan, Nepal

Corresponding Author: Mannu Vikram, Associate Professor Department of Conservative Dentistry and Endodontics B.P. Koirala Institute of Health Sciences, Dharan, Nepal, Phone: +009779852049808, e-mail: drmannuvikram@gmail.com apex. Apical extrusion of debris may occur not only in routine endodontic cases, but also during retreatment of failed endodontic cases. ${ }^{1}$ Although better cleaning, shaping, and microbial control have allowed endodontic therapy improvements, some adverse situations occur, which may delay proper healing. Failure may occur due to any step in the root canal treatment like improper biomechanical preparation, obturation, or irrigation. ${ }^{2}$ Therefore, adequate care is needed in all the procedures entailing a root canal treatment for better outcomes.

During endodontic retreatment, various irritants may be extruded through the foramen. ${ }^{3,4}$ Filling materials, necrotic tissues, bacteria, or irrigants may be undesirably introduced into the periapical tissues. ${ }^{5}$ The extrusion of these materials may potentially cause damage, such as postoperative pain, flare-ups, foreign body reaction, and even failure in the lesion repair.

At present, root canal preparation with motor-driven nickel-titanium (NiTi) instruments has become frequent. ${ }^{6}$ Nowadays, the modern design of the instruments with noncutting tips, different cross-sections, and several tapers has been developed to offer a safer and faster procedure. All instrumentation techniques, regardless of the material used, performed either only within the root canal or surpassing the apical foramen, cause debris extrusion. ${ }^{7}$ However, the amount of apically extruded debris may vary according to the technique used. ${ }^{3}$ Consequently, proper retreatment techniques should be selected to remove as much previous filling material as possible, with the minimum debris extrusion for the periapical tissues.

Therefore, the main objective of this study was to study and compare the amount of apical debris extrusion using stainless steel K-files and NiTi Protaper files.

\section{MATERIALS AND METHODS}

Sixty mandibular first premolar teeth having a single root and a single canal were selected, and their radiographs were taken to confirm the presence of a single root and canal. Thereafter, the teeth were decoronated at the cementoenamel junction. Working length was established by introducing a $20 \mathrm{~K}$-file into the canal. When the tip of the file was just visible beyond the apical foramen, the length was recorded. About $1 \mathrm{~mm}$ was subtracted from this length to get the final working length. 
All the 60 teeth were instrumented with stainless steel K-files in a crown-down manner. The apical stop was prepared until a size of $30 \mathrm{~K}$-file. In between the use of successive instruments, frequent irrigation and recapitulation were performed. Irrigation was done with $2.5 \%$ sodium hypochlorite, saline, and $17 \%$ ethylenediaminetetraacetic acid. All the teeth were then obturated with gutta-percha using the lateral condensation method. Zinc-oxide eugenol was used as the sealer.

Empty Eppendorf tubes were weighed with a precision analytic microbalance (0.0001 gm accuracy level). Three consecutive measurements were taken for each tube, and the mean value was recorded. An opening was made in the stopper of the preweighted Eppendorf tube, and tooth was inserted under pressure through the stopper, which will be fixed with cyanoacrylate. A bent 24-gauge needle was forced alongside the stopper to use as a drainage cannula, and balance the air pressure inside and outside the tube. The Eppendorf tubes were then fitted into the vials. The vials were covered with aluminum foil to prevent the operator from viewing the debris extrusion during the procedure.

In group I, retreatment was started using stainless steel K-files after the teeth were fitted into the already setup Eppendorf tubes and vials. Xylene was used as gutta-percha solvent. Similarly, in group II, retreatment was carried out using Protaper retreatment files.

Following instrumentation, the Eppendorf tubes were removed from the vial. The debris adhered to the external surface of root apex were collected by washing off with distilled water into the tube. The tubes were then stored in an incubator at $37^{\circ} \mathrm{C}$ for 21 days to drive off all the moisture. The tubes were again weighed three times each, and the average value was calculated. The weight of extruded debris in each tube was calculated by subtracting preexperiment weight of the tube from the weight of the tube with dried debris, and the mean weight of extruded debris was calculated for each group.

\section{RESULTS}

All the 60 teeth in which instrumentation was carried out showed extrusion to varying degrees. The difference in the initial and final weighing of the groups was statistically analyzed by Tukey test. In group I, the mean value was $0.07 \mathrm{gm}$, whereas in group II, the mean value was $0.02 \mathrm{gm}$, which was statistically significant ( $\mathrm{p}$-value $<0.05$ was considered as significant) (Table 1).

\section{DISCUSSION}

Apical extrusion of debris is an unavoidable occurrence during root canal treatment. ${ }^{8}$ The extruded debris may not only be the dentinal and necrotic material of the root
Table 1: Values obtained for the two groups (in grams)

\begin{tabular}{llll}
\hline & $\begin{array}{l}\text { Mean weight of } \\
\text { the 30 Eppendorf } \\
\text { tubes before }\end{array}$ & $\begin{array}{l}\text { Mean weight of } \\
\text { the 30 Eppendorf } \\
\text { tubes after debris } \\
\text { Groups }\end{array}$ & $\begin{array}{l}\text { Difference } \\
\text { of the mean } \\
\text { collection }\end{array}$ \\
\hline I & 0.04 & 0.11 & weights \\
II & 0.04 & 0.06 & 0.07 \\
\hline
\end{tabular}

canal, but also the gutta-percha and sealer in cases of root canal retreatment procedures. Regardless of the technique and instruments used, apical extrusion of debris is inevitable. As far as possible, one of the aims of the treatment should be to minimize the extrusion of debris to as little as possible. The extrusion of debris acts as a foreign material in the periapical tissues, and this causes periapical inflammation. ${ }^{9}$ This inflammation is the cause of most of the postoperative pain and flare-ups, which the patient reports in the endodontic clinic.

As it is difficult to do such a study under in vivo conditions, therefore, extracted teeth were used in this study to simulate the clinical conditions as far as possible. Stainless steel hand files, such as the K-files have been used since a long time. With the advent of NiTi rotary files, treatment time has been cut down to a great extent. This study was carried out to compare the apical extrusion of debris during retreatment procedures using stainless steel hand K-files and NiTi rotary Protaper retreatment files.

The Protaper retreatment files are designed in such a way that although there are three points of contact with the root canal dentinal wall, there is ample space between the instrument and the walls to accommodate the fragmented debris unlike the hand files. ${ }^{10}$ This is possible because of the convex triangular design of the files when viewed in cross-section. Thus, the NiTi rotary Protaper files extrude significantly lesser amount of debris apically as compared with stainless steel hand K-files.

\section{CONCLUSION}

It can be concluded from the results of the study that although both stainless steel hand file and rotary Protaper retreatment files extrude debris apically, in the latter case, there is significantly lesser amount of extrusion.

\section{REFERENCES}

1. Paik S, Sechrist C, Torabinejad M. Levels of evidence for the outcome of endodontic retreatment. J Endod 2004 Nov;30(11):745-750.

2. Mandel E, Friedman S. Endodontic retreatment: a rational approach to root canal reinstrumentation. J Endod 1992 Nov;18(11):565-569.

3. Reddy SA, Hicks ML. Apical extrusion of debris using two hand and two rotary instrumentation techniques. J Endod 1998 Mar;24(3):180-183. 
4. Imura N, Kato AS, Hata GI, Uemura M, Toda T, Weine F. A comparison of the relative efficacies of four hand and rotary instrumentation techniques during endodontic retreatment. Int Endod J 2000 Jul;33(4):361-366.

5. Tinaz AC, Alacam T, Uzun O, Maden M, Kayaoglu G. The effect of disruption of apical constriction on periapiacal extrusion. J Endod 2005 Jul;31(7):533-535.

6. Bergmans L, Van Cleynenbreugel J, Wevers M, Lambrechts P. Mechanical root canal preparation with NiTi rotary instruments: rationale, performance and safety. Status report for the American Journal of Dentistry. Am J Dent 2001 Oct;14(5):324-333.
7. Er K, Sumer Z, Akpinar KE. Apical extrusion of intracanal bacteria following use of two engine-driven instrumentation techniques. Int Endod J 2005 Dec;38(12):871-876.

8. Stabholz A, Friedman S. Endodontic retreatment - case selection and technique. Part 2: treatment planning for retreatment. J Endod 1988 Dec;14(12):607-614.

9. Lopes HP, Siqueira JF Jr. Endodontia - biologia e técnica. Rio de Janeiro: Medsi; 1999. p. 650.

10. Huang X, Ling J, Wei X, Gu L. Quantitative evaluation of debris extruded apically by using protaper universal tulsa rotary system in endodontic retreatment. J Endod 2007 Sep;33(9):1102-1105. 